THE EFFECTIVENESS OF A PROPOSED ARAB CULTURE APPROACH

FOR THE SPEAKERS OF OTHER LANGUAGES TO LEARNING THE

\author{
ARABIC LANGUAGE \\ Muna ARAFA ${ }^{1}$, Farida BADR ${ }^{2, *}$ \\ ${ }^{1}$ Curriculum Department, Faculty of Education, Helwan University, Egypt. \\ ${ }^{2}$ Department of Culture and Society, Aarhus University, Denmark.
}

\begin{abstract}
The origins of peoples of the world are myriad and each language is as different in its origin formation, but there are languages similar enough in source and formation, on which several cultures established societies. The general concept of culture is a group of living patterns and practices of acquired attitude or transmitted by codes, writings, and works that require a common language by which to read and circulate them among the people of a society.
\end{abstract}

Keywords

Arab Culture, Arabic Language, Humanitarian, Linguistic Skills, Curriculum.

\title{
Introduction
}

The origins of peoples of the world are myriad and each language is as different in its origin formation, but there are languages similar enough in source and formation, on which several cultures established societies.

The general concept of culture is a group of living patterns and practices of acquired attitude or transmitted by codes, writings, and works that require a common language by which to read and circulate them among the people of a society.

Language represents an important element of expressing cultural identity, but it strongly combines with the ideas produced by the culture, embodied in works of architecture and art, among others, and achievements that create a vision and civilization that expresses the perspective of the society. (Muna Arafa, 2015,74:76).

Language represents an important core in establishing the humanitarian culture and a basic structure for formatting the humanitarian relationships that spread via geographical borders, contributing to the understanding and learning of other cultures and facilitating their discovery. Language is the spirit and life of a nation whereas nationality is the core and spine. One of its important factors and characteristics, as well as being the container that protects the nation's heritage and values, it is that it allows the people of the nation to connect with their roots and history.

Teaching the Arabic language to non-native speakers is the question of the current research; it is unique in its identity and formation due to the fact that it "represents the Holy Quran language

*Corresponding author: cas@au.dk 
and the divine religion in general." Non- Arab peoples want to learn it for two main reasons:

1. To memorize the Quran and Prophetic Hadith and understand stories and poetry.

2. The cultural and scientific communication among Arab peoples and the western peoples. (Muhammad Bekhir Al-Haj, 2009)

Because the language is so integrated, many people all over the world are extensively concerned with learning the Arabic language and how to understand it correctly. It has become a researched and studied subject and researchers have devised several methods, techniques, and curricula to ease learning it for non-native speakers to both understand and solve problems in the language in various fields, including but not limited to:

On Yon's study (2012) focused on the duplicity phenomenon in the Arabic language and the researcher submitting a suggestion to solve it. This phenomenon causes a big obstacle against understanding the meaning and syntax of the Arabic language for non-native speakers, which has to be connected with the cognitive experience of the culture.

At the same time, the study of (Abd El-Rahman Bin Saad Al-Sarami, (2014) discussed the importance of concentrating on learning linguistic skills for non- native speakers by designing an electronic Web site. He advised on the importance of activating and integrating the international Web with the Arabic language learning Web sites for non-native speakers and setting up comprehensive quality standards for such Web sites because they may have a role for activating some cultural effects that enhance the language.

Both studies indirectly illustrated the cultural element and its effect on learning the Arabic language, which I believe has a huge effect in learning and realizing the linguistic diversity of the Arabic language and its vocabularies and meanings affected by its identity.

The comprehensive meaning of language isn't just vocabularies of phrases in writings but customs, traditions, ethics, thinking, legislation and behavior, civilization, and culture; it's it conveys the nation's mental and emotional life. (Muna Arafa, Eman Al-Safori, 2014).

If the curricula of the Arabic language includes parts of Arab heritage and derives its poems and texts from various Arab literary arts throughout its historical eras, this will support the learning of the student who wishes to become an adept language speaker.

Both researchers did exploratory experiments using the closed questionnaire on a random sample of students in different educational stages to make sure of the curriculum of Arabic language (see Table 1):

- $\quad$ How the curriculum achieved the educational aims of students.

- The scientific content studied by students and its connection to the Arab culture and the language practices. 
- $\quad$ Strategies used by the instructor in teaching the content and how it suites students' learning.

Educational aids used to apply the curriculum scientific content to students.

How the cultural aspects are available and their connection with practicing the language.

Table (1) Results of Questionnaire to Students about Arabic LanguageCurriculum

\begin{tabular}{|c|c|c|c|c|}
\hline S. & Questionnaire Core & $\begin{array}{c}\text { Items } \\
\text { Count }\end{array}$ & Available & Unavailable \\
\hline 1 & Educational aims & 4 & $55 \%$ & $45 \%$ \\
\hline 3 & $\begin{array}{c}\text { Scientific content in } \\
\text { the light of culture } \\
\text { in the light of culture }\end{array}$ & 6 & $42.5 \%$ & $57.5 \%$ \\
\hline 4 & $\begin{array}{c}\text { Educational aids } \\
\text { used in the light ofculture }\end{array}$ & 7 & $35.8 \%$ & $53.4 \%$ \\
\hline 5 & $\begin{array}{c}\text { Cultural aspects andtheir } \\
\text { connection to the } \\
\text { language } \\
\text { practices }\end{array}$ & 10 & $25.9 \%$ & $74.1 \%$ \\
\hline
\end{tabular}

The results of Table 1 demonstrated that there is deficiency in the implementation of curriculum language cultural practices that provide techniques and strategies that contribute to the achievement of curriculum aims and facilitate student's learning.

Throughout doing this exploratory experiment about the curriculum in North Carolina University, it has appeared that there is a gap between Arabic language learning and its connection to culture.

\section{Research Issue:}

The research issue has concluded that the curriculum content of Arabic language for non-native speakers doesn't focus enough on the Arab culture aspects to promote the learning of language by using media of cultural Arab heritage and the mechanism of applying them to support the development of the feeling and interrelation of the language that eases the learning of non-native speakers. 


\section{Research Inquiries:}

The current research tries to answer the following inquiries:

Q: What is the actuality of the cultural heritage offerings in the Arabic language curriculum for non-native speakers in North Carolina University and its achievement of educational aims?

Q: What are adequate heritage culture fields that can support Arabic language learning?

Q: What is the form of the proposed curriculum to develop some aspects of Arabic culture supporting Arabic language learning for non-native speakers in North Carolina University?

\section{Research Aims:}

The current research aims to:

Prepare a curriculum to develop some aspects of Arabic culture that will support Arabic language learning for non-native speakers in the light of domestic economy - the knowledge and practice of life- by connecting the Arabic language to the Arab culture, which wasn't promoted before in the curriculum of students in North Carolina University.

\section{Research Importance:}

The current research is important because:

1- The research is an actual response to several studies seeking to facilitate learning of the Arabic language for non-native speakers and confirm the importance of Arab culture for achieving these educational aims.

2- $\quad$ The current research may impress on those planning and preparing Arabic language curricula for non-native speakers the importance of connecting the language to the cultural heritage, which in turn boosts the learning of the language for non-native speakers.

3- The proposed curriculum in the current research may present a vision in the light of the Arab culture to educate non-native speakers and presents new suggestions to the curriculum including a list of cultural heritage aspects that can contribute to learning the Arabic language for non-native speakers in other countries.

4- The current research presents a vision supporting the connection between sciences, especially domestic economy (life knowledge), which can help present the cultural heritage identifying the life reality and present a number of strategies to enhance the language learning through living cultural practices that contribute in learning retention.

\section{Research Limits:}

The current research has the following limitations:

1- It used an exploratory sample of students of North Carolina University learning the Arabic language in various educational stages, and instructors who teach the Arabic language for non-native speakers. 
2- A list of Arab cultural aspects in the light of domestic economy supporting Arabic language for non-native speakers.

\section{Research Terms:}

\section{Arab Culture:}

Culture is a group of values, verbal and non-verbal codes shared by a large number of people. Cultural contact happens when one or more people of a certain culture come into contact with one or more persons of another culture.

Muhammad Al-Hadi Afifi, (1983) mentions a comprehensive definition of culture In his point of view, culture means "Whatever made by human in his environment during his long history in a certain society, including the language, customs, values, general attitude ethics, tools, perception, social levels, social, economical, politic, educational and judicial systems. It represents the original expression of historical privacy of a nation and the nation view to the universe, life, death, human and his abilities and what he has to do and what he doesn't have to do nor hope.".

Muhammad Faidhi, (2015) defined culture as the intellectual heritage that distinguishes nations, whereas the cultural nature and features differ from a one society to another, because of the close association between the nation reality and its intellectual and civilizational heritage. Non-Native Speakers of Arabic Language:

They are the persons who desire to learn the Arabic language for a scientific or a personal purpose.

\section{Framework:}

\section{Culture and Arabic Language:}

Culture is a group of apparent or hidden patterns of the acquired or transmitted attitude by codes, in addition to distinguished achievements of humanitarian communities represented in the popular heritage. Based on this definition, we deduce that the heritage is a humanitarian appearance expressing peoples' culture and embodying their identities. The culture grants any community its character and identity, which differ from and are known to other communities, "as well as being relative and scalable".(Seham Nassar, 2013).

Muhammad Al-Hodi's (1983) definition represents the original expression of the historical privacy of a nation. According to this definition, we deduce the close connection between the language and the culture and the impossibility of separating the language and learning it without context.

(Angela Little (2013) has emphasized in her study that understanding the culture of the learning society environment is a prior condition to achieve effective learning for learners because it's 
the key that brings understanding to the learner and emphasizes his identity, as well as helping the discovery of new teaching strategies. Arabic language associates with the Islamic civilization identity and historical and social features, from which the language obtains values, customs, and tradition, "and the accumulated cultural heritage throughout sequence historical epochs, moreover the nation interact with developments contribute in forming the nation cultural identity" (Attia Abu Al-Sheikh, 2008, p. 645).

The following figure illustrates the culture features and heritage, in which the language represents one of main medias of transmitting the culture:

Popular Beliefs-Customs and Traditions-Popular Art-Popular literature.

Associated phenomenon, medicine and pealing-Manifestations of behavior and patterns passed down by generation of food, clothing and aphorisms and celebrations-Handcrafts-DancingSigning-Theatre-Handicraft items-It's moved to express oral and writing.

Humanitarian-social-integrated-acquired-removable- saturated to the need of- variable and sophisticated.

The culture represents a main element in the learning of society-it is the cultural arts over eras that are the basic pillars for the continuity of a people and a culture. Customs, traditions, values, conventions, beliefs, ethics, and arts remaining with a person from birth, and no matter where in the world they go, these cultural teachings will influence the way s/he interacts with the world.

The current research has discussed the heritage with its various expressions and elements of the Arab culture as one of the main pillars of supporting Arabic language throughout a student's learning experience, enabling the learner to study the language in context. The benefits are as follows:

- The culture helps formation of a general cognitive basis for the learner through which he learns about how the environment influences the language.

- The culture features in a dynamic form interact with the society lineaments; its folklore heritage represents performing arts, represented by a simple language, and expresses the perspective of the people in the society.

- The popular heritage of culture connects to a group of effective educational and sensual media, which greatly contribute in open communication channels between the learner and the learning experience.

There are studies that support this vision of learning, such as the study of Salam (1883, p. 88), which affirmed the necessity that the teacher must realize that the language is an integrated unit to use linguistic lessons to help learners learn the language and its culture and acquire its skills. 
(The Popular Culture Magazine (2013, p. 2) presented a proposed model to insert the Arab popular culture as an independent academic subject in the education curricula because teaching Arab civilization and heritage achieves the optimal balance for effective Arabic language learning.

On this ground, the cultural formation can be deduced by the Figure 1, which is that the language and the social formation including customs, traditions, conventions, and religious formation with its beliefs, values, and organizations have a significant relationship to the aesthetic formation of the society, including ethics, arts, innovative vision, technology productivity, and cognition. Suhail Salaman, (2008, p. 540; Muhammad Al-Dawdi, 2005, p. 39)

Accordingly, the culture is strongly associated with the language growth and inveteracy, and if we pay attention to it in teaching the language to non-native speakers, it will ease their learning throughout, representing an actual experience lived by the learner. We can deduce the importance of that vision in the following points:

1- The culture and its heritage provide an applied form to the life lineaments and activities.

2- It helps the learner get into the trial and an actual practice of heritage aspects that contain methods and techniques facilitating the language learning, where the learner can learn through the practice and remember the linguistic terms faced by him during acquiring the cultural experience.

3- It contributes in solving linguistic terms problems - the Arabic language enjoys a lot of such terms (Standard-slang-colloquial).

4- $\quad$ Culture provides a rich environment to the learner in all life fields.

The role of culture can't be separated from Arabic language, and this is a fact can't be neglected. The Arab culture consists of two main components: Arabic language and Islamthat is why some people insist on naming it "The Islamic Arab Culture." The language is the container of all sciences, and the instrument of explaining all scientific, technical, and ordinary expressions. It is the device of affecting the brain and feeling its literature, prose, poetry, aphorisms, proverbs, stories and legends, and the rest of its artistic types and tools. (Wikipedia Encyclopedia, 2015).

Domestic Economy Science as an Analytical Introduction of Culture and its Scientific Practice in Life:

Domestic Economy is the knowledge of life specialized in studying the family needs and essentials, the family at the level of house, environment, and society, aiming at advancing it to a cognation life at the social level. At the scientific level, it boosts humane innovation and 
development over history by introducing a continual interaction with humanitarian civilization and its production in different life fields.

When this science is connected to edification and culture, it will represent channels of analyzing, developing, and innovating production, which presents solutions to problems of the scientific life, and a multi-tunnels arch to develop the human being's life.

The culture connection to the educational domestic economy represents an interaction network that can't be separated and disperses custom, traditions, and intellectual and scientific production by the scientific, applied treatments done by its science fields (the educational domestic economy and humane thought, nutrition and foods science, clothes and textile, family, childhood, institutions administration, and other fields).

The educational curriculum connects to ideologies of society and the learner in terms of formatting its content, so the analysis of such ideologies derive only from the culture and its heritage aspects. Figure 2 illustrates the cultural heritage fields:

Language and arts are indicators of the values, beliefs, customs, and traditions that are transmitted from one generation to the next by the associated interaction with the culture properties, which need a scientific treatment for reformulating language and providing it in an easy language of society especially with life development and progress.

\section{The research sample:}

- $\quad$ Male and female students of North Carolina University.

- $\quad$ Staff members with their different majors in the faculty of home economics.

The research limits:

- $\quad$ Arabic curriculum for the non-native speakers in North Carolina University.

- The fields of cultural Arabian Heritage in the light of scientific treatment of home economics.

\section{Research tools:}

1- A form of analyzing the Arabic curriculum for non-native speakers in the light of curriculum and culture components.

2- $\quad$ Setting a list of Arabian culture aspects that may be developed by the curriculum and may support Arabic language learning.

3- $\quad$ Setting a proposed curriculum for developing Arabian culture aspects that support Arabic for their non-native speakers.

The research curriculum and its procedures:

This research belongs to the category of descriptive research; its procedures are conducted according the following steps: 
Determining the fields of Arabian cultural that support developing Arabic in the light of treating Home Economics by referring the following resources:

- $\quad$ viewing studies addressing heritage and its popular treatment of Home Economics.

- $\quad$ analyzing the content of the Arabic curriculum in the light of Arabian cultural.

- $\quad$ determining the fields of folklore that fit the methods and strategies of learning Arabic.

- $\quad$ setting a preliminary visualization of the list of cultural heritage fields on which academic units will be based in the light of treating its including subjects in the fields of Home Economics.

making a poll of a set of Arabic lecturers in North Carolina University on fields of cultural heritage and its content which its study may fit students.

- $\quad$ designing Arabic curriculum units for its non-native speakers.

- $\quad$ showing a map of Arabic curriculum for a set of Messrs arbitrators for recognizing their suitability for aims of learning Arabic and developing its skills.

\section{Research procedures:}

First: A questionnaire of correlation between the Arabic curriculum and culture is set to answer the first question, "what is the reality of cultural heritage in Arabic curricula for non-native speakers in North Carolina University and how does it achieve the educational aims?"

Fields of Arabian cultural heritage and its sections are determined in the light of popular treatment of Home Economics by which life applications may be provided and applied with students easily for supporting Arabic learning.

* The list has an agreement rate that is limited between (90: and 100\%) for all phrases, with conducting some simple modifications in formulating the phrases.

* A questionnaire is distributed to seven Arabic lecturers in North Carolina University for viewing the reality of setting the Arabic curriculum in the different learning stages of Arabian culture. The following table indicates the questionnaire.

Table (1) The survey percentage of a number of Arabic lectures in Carolina University.

\begin{tabular}{|c|c|c|c|c|c|c|}
\hline & Content of & Content of & $\begin{array}{c}\text { Content of } \\
\text { learning and }\end{array}$ & Content of & $\begin{array}{c}\text { Content of } \\
\text { curriculum }\end{array}$ & Content of \\
educating & assessment & teaching \\
scientific & Learning & teaching & strategies & ways and & aids. \\
subject & sources & activities & & Methods & \\
\hline
\end{tabular}




\begin{tabular}{|c|c|c|c|c|c|c|c|c|c|c|c|c|c|}
\hline & & 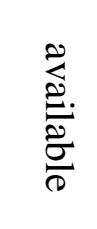 & 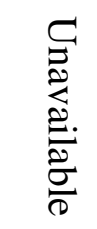 & 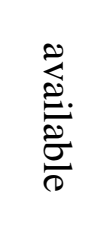 & 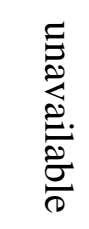 & 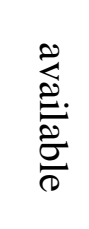 & 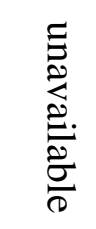 & $\begin{array}{l}\stackrel{2}{2} \\
\stackrel{0}{*} \\
\frac{\tilde{\sigma}}{0}\end{array}$ & 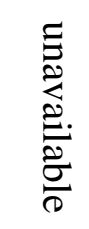 & $\begin{array}{l}\stackrel{2}{2} \\
\stackrel{2}{*} \\
\frac{\tilde{\sigma}}{0}\end{array}$ & 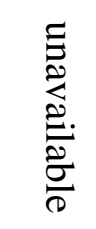 & 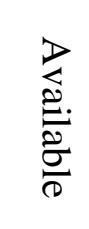 & 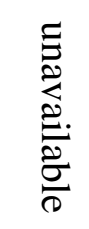 \\
\hline $\begin{array}{l}\overleftrightarrow{\S} \\
\stackrel{f}{H}\end{array}$ & 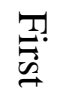 & 22.2 & 77.7 & 33.3 & 66.6 & 22.2 & 77.7 & 44.4 & 55.5 & 11.1 & 88.8 & 11.1 & 88.8 \\
\hline $\begin{array}{l}\overleftrightarrow{円} \\
\stackrel{\sharp}{\sharp}\end{array}$ & $\begin{array}{l}\tilde{D} \\
\mathbb{\infty} \\
\delta \\
0\end{array}$ & 33.3 & 66.6 & 33.3 & 66.6 & 22.2 & 77.7 & 22.2 & 77.7 & 11.1 & 88.8 & 11.1 & 88.8 \\
\hline $\begin{array}{l}\overleftarrow{\varnothing} \\
\stackrel{\overbrace{}}{H}\end{array}$ & $\stackrel{\vec{E}}{\overrightarrow{0}}$ & 33.3 & 66.6 & 22.2 & 77.7 & 44.4 & 55.5 & 44.4 & 55.5 & 44.4 & 55.5 & 33.3 & 66.6 \\
\hline 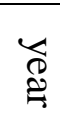 & 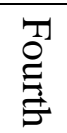 & 33.3 & 66.6 & 22.2 & 77.7 & 44.4 & 55.5 & 11.1 & 88.8 & 22.2 & 77.7 & 33.3 & 66.6 \\
\hline
\end{tabular}

Questionnaire results indicate that the percentage of reality unavailability in Arabic curriculums in different learning stages are limited between $66.6 \%$ and $88.8 \%$. The table indicates the following:

- the scientific content treatment of the correlation between Arabic and its culture unclearly.

- $\quad$ the available learning resources don't support learning Arabic by cultural applications.

- $\quad$ analysis results have shown that teaching Arabic for non speakers is treating linguistics practices application superficially and away from the simplest meaning of culture as a concept that expresses human application of Arabian culture. There is a confusion of the concept between Arabian cultural activities and general practice.

Second: Setting a list in the fields of cultural heritage that support Arabic curriculum in the light of Home Economics treatment to answer the second question of the research questions "what are the appropriate heritage fields of culture that can support learning Arabic?"

- $\quad$ the female researcher has viewed the scientific material of folklore and she has collected several heritage books collected from different countries that are available in the center of social studies and researches, the general authority of books and heritage electronic library, and from some records.

- $\quad$ the female researcher has displayed a questionnaire to a set of arbitrators in Egypt and some Arab countries like Bahrain, Iraq, Kuwait, Algeria, and Saudi Arabia for verifying the following: the suitability extent of heritage material and its treatment in the light of Home Economics. 
THE EFFECTIVENESS OF A PROPOSED ARAB CULTURE APPROACH FOR THE SPEAKERS OF OTHER LANGUAGES TO LEARNING THE ARABIC LANGUAGE

Table (2) A questionnaire about Folklore fields that fit supporting Arabic.

\begin{tabular}{|c|c|c|}
\hline Folklore fields & Number of arbitrators & Agreement percentage \\
\hline Popular tales & 12 & $98 \%$ \\
\hline Popular games & 12 & $96 \%$ \\
\hline Popular biography & 12 & $85 \%$ \\
\hline Popular fashion & 12 & $100 \%$ \\
\hline Popular food & 12 & $96 \%$ \\
\hline Customs and traditions & 12 & $95 \%$ \\
\hline Popular songs & 12 & $100 \%$ \\
\hline
\end{tabular}

The last table indicates the rise of agreement percentage on the applicable content of folklore fields and comments of others on important points to be considered.

Third: setting the proposed visualization of family education in the light of values that support positiveness in knowledge society to answer the third research question.

\section{Setting curriculum:}

1- Philosophical basis on which the proposed visualization of setting family education curriculum is based on:

- $\quad$ Arabic curriculum of different educational stages is set in the light of Arabian culture.

- $\quad$ taking into account the nature of Arabic that is related closely to cultural life practices.

* other bases of building the proposed curriculum:

A- The concept of culture and its importance.

B- The nature of Arabic and the objectives of its teaching to all educational stages.

C- The nature of male and female students of educational stages.

D- The nature of American society and cultural variance.

* The steps of setting the proposed curriculum (for educational stages):

A- Determining the general targets from which behavioral objectives (cognitive, skill, and emotional) emerge.

B- Determining the proposed visualization content in the light of philosophical perspectives and general objectives, and then determining the curriculum content by the following:

- $\quad$ in the light of philosophy and curriculum objectives.

- $\quad$ relying in derivation of content elements on modern scientific resources.

- $\quad$ focus on integrating the values that support positiveness in Knowledge society.

- $\quad$ organizing content in curriculum scheme. 
C- Taking into account the curriculum quality represented in:

1- Inclusiveness: it addresses all different aspects in building, designing, developing, implementing, and assessing the curriculum.

2- Objectivity: it must be provided when assessing the availability of its objectives. 3Flexibility: taking into account all levels and all environments.

4- Societal: it promotes the society's needs, circumstances, and issues.

5- Continuity and development: it is the possibility of its application and amendment. 6Achieving the principle of participation in design and taking decisions.

* determining the teaching ways and strategies:

- $\quad$ choosing the suitable modern ways and strategies that fit lessons and topics of content and support developing values for achieving the desired objectives.

* determining the educational methods and learning resources of the curriculum proposed visualization:

- Multimedia

- Internet

-photographs and films.

* formulating the educational activities in the proposed curriculum (educational stages).

* determining assessment methods (formative- progressive- final).

* Curriculum units:

The curriculum of stages of primary education includes six units. Each unit supports a value of the values that support positiveness in the knowledge society and its subjects graduates according to the educational stage as follows:

The treatment levels are included at all cultural heritage fields in its life fields, sections, and activities, which facilitates understanding and comprehending the language that expresses the nature and culture of each human language.

\section{Results and Discussion}

1- $\quad$ Setting a proposed list in the cultural heritage fields that is treated in the light of Home Economics to support learning Arabic.

2- $\quad$ Providing a proposed scheme for setting Arabic curriculum in the stages of university education.

\section{Recommendations:}

1- $\quad$ The necessity of the correlation between life sciences and languages learning.

2- Conducting a practical experience of the curriculum in the form of a program in home economics in order to support developing and facilitating Arabic learning and experience 
generalization..

\section{References}

1- Ahmed Kanaan: the role of educational curriculum in Arabic Republic of Syria in activating the Arabian approximation "" analytical study in Arabic curriculum in the two stages of university education and pre-university education" the seventeenth annual national conference (the ninth Arabian one), 10-11 November 2010.

2- Soheel Salem Salman: The Role of art education in promoting the values and highlighting the cultural identity at the kingdom of Saudi Arabia. Twentieth scientific conference, learning curriculums and cultural identity, volume 2, 30-31 July, Ain Shams University, 2008.

3- Abd El-Rahman Ibn Saed Al-Sermatty: evaluating Arabic sites for non-native speakers on the internet in the light of linguistics skills, Master thesis, the Islamic University of Imam Mohamed Ibn Saud, Kingdom of Saudi Arabia, 2014.

4- Mona Arafa Abd El-Wahab: developing the Arabic approximation in Home economics by a program that is set on aspects of Arabian folklore in the stage of kindergarten, Doctorate thesis, Home economics faculty, Helwan University, 2015.

5- Mona Arafa Abd El-Wahab, Eman Al-Safoury: a heritage aspect in an educational perspective for developing the affiliation as one of Arabian approximation contents for kindergarten child in the light of home economics, the second international conference in the faculty of Home economics, 5-7 may, the faculty of home economics, Helwan University, 2014.

6- Mohamed Al-Daweidy: localizing translation "the tools of creative knowledge, studies and researches of Arabian forum for translation "the translation in the Arab world " the reality and the hopes, the Arab Thought Foundation, Kerky printing house, Beirut, 2005.

7- Mohamed Al-Hady Afifi: in the basics of education "the cultural basics of education", Anglo Egyptian Library, Cairo, 1983.

8- Mohamed Beikher Al-hag: the theoretical and applicable problems in learning Arabic for non-native speakers, the magazine of Islam in Asia, edition 1, volume 6, 2009.

9- Mohamed Faidy: the culture definition, the topic of "Read in Arabic", 2015, http://mawdoo3.com/\%D8\%AA\%D8\%B9\%D8\%B1\%D9\%8A\%D9\%81_\%D8\%A7\%D9\% 84\%D8\%AB\%D9\%82\%D8\%A7\%D9\%81\%D8\%A9

10- Youn On Kiong, the best curriculum for learning Arabic for non-native speakers in the perspective of sociology, the professor magazine, edition 201, in $1433 \mathrm{AH}, 2012$.

11- Reham SHALABY, THE CREATIVE ROLE OF PLASTIC ARTS IN THE FACE OF 
DISCRIMINATION AND VIOLENCE AGAINST WOMEN, International Journal of Humanities and Language Research, Vol. 2, No. 2, 2019, pp. 1-8.

12- Wissam Hassan HASHEM, THE DESIGN PERFORMANCE OF INTERNAL SPACES AND ITS RELATIONSHIP TO THE SOCIAL VARIABLE: BAGHDAD CAFES ARE A MODEL, International Journal of Humanities and Language Research, Vol. 2, No. 2, 2019, pp. 9-19.

Received: March 3, 2020

Accepted: May 25, 2020 